\title{
Role of Nanomaterials in Cosmeceuticals: Challenges, Development Strategies, and Future Perspective
}

\author{
Swatantra Kushwaha ${ }^{1, * i D}$, Ashutosh Kumar Pandey ${ }^{1(D)}$, Neelottama Kushwaha ${ }^{1(D)}$ \\ 1 Department of Pharmacy, Pranveer Singh Institute of Technology, Kanpur-209305, India; \\ swatantrakushwaha15@gmail.com (S.K.); ashutosh11497@gmail.com (A.K.P.); neelottama@gmail.com (N.K.); \\ * Correspondence: swatantrakushwaha15@gmail.com (S.K.);
}

Received: 17.07.2021; Revised: 28.08.2021; Accepted: 4.09.2021; Published: 30.10.2021

\begin{abstract}
Nanotechnology is the most trendsetting innovation in the 21 st century. In this new technology, industries are also developing new formulations combined with nanotechnology. In the 'Nanocentury' nano and cosmetic are combined and developed cosmeceuticals like cream for wrinkling, hyperpigmentation, skin inelastic, and dehydration. We also know the history of cosmetics or their development from 4000 BCE to the 21st century. Such include also type of nanotechnology according to their particle size and uppermost use of bio cosmetics.
\end{abstract}

Keywords: nanomaterials; cosmeceuticals; nanocapsule; nanocrystal.

(C) 2021 by the authors. This article is an open-access article distributed under the terms and conditions of the Creative Commons Attribution (CC BY) license (https://creativecommons.org/licenses/by/4.0/).

\section{Introduction}

The most advanced technology is nanotechnology contemplated innovation in the twenty-first century, and it is also considered in the cosmetic industry [1]. Nanotechnology is a term made up of two words nano means dwarf, and technology means the science of craft. In this type of technology, particles range from 1 to $100 \mathrm{~nm}$ [2].

Nanotechnology has been around since 1959 and has been used in several disciplines, including pharmaceutical, chemical composition, biology, and scientific knowledge. Nanotechnology is an opportunity to enhance delivery and targeting and produce new devices and new materials [3]. In nanotechnology, nonmaterial's are used; they are two types of techniques.

\subsection{Techniques from the top down.}

In nanotechnology, the term 'top-bottom' relates to the machining 'process's the physical crushing of raw resources, as shown in figure 1.

\subsection{Bottom-up.}

This process is also called chemo-physical production. Here atoms are self-organized and approach to produce complex structures for better size and shape of the product, as shown in figure 2. 
Figure1. Technique of top-down.

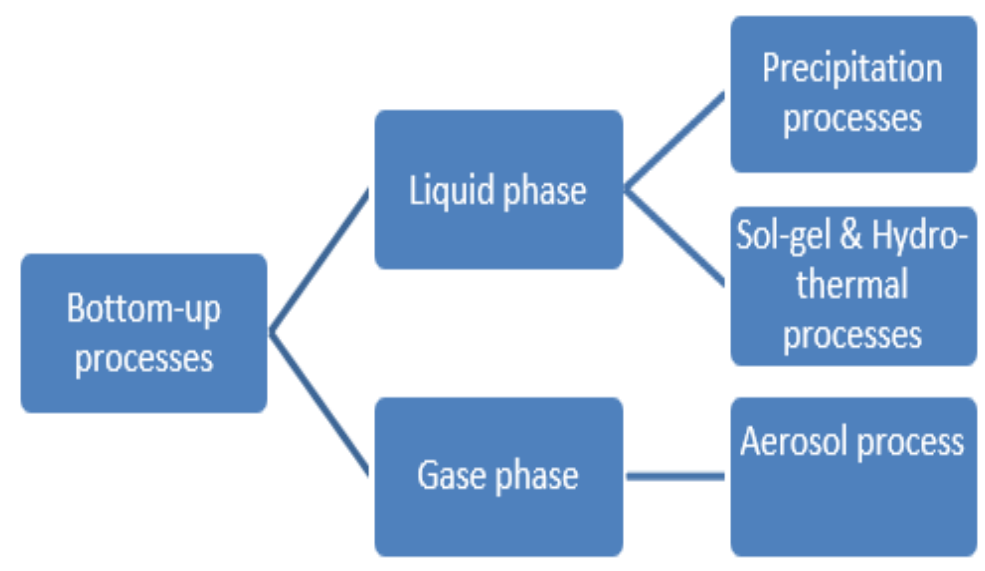

Figure 2. Phase and process of bottom-up.

On the need of cosmetics, they could classify as: 1. Skincare product, e.g., cleansing agent, moisturizer; 2. Face care products, e.g., face powder, lipsticks, mascara, face foundation; 3. Haircare product, e.g., hair dye or color, hair gel, shampoo, hair spray; 4. Nail care product, e.g., paint remover; 5. Products with fragrance, e.g., Antiperspirants, skincare products, and fragrances, are all examples of colognes; 6. Fluoroscope light screening product, e.g., sunscreen.

\subsection{History of cosmetics.}

Cosmetic is widely used in the world. This is how Plautus, a Roman playwright, phrased it: "Without the paint (cosmetics), a lady is like bread without salt". Cosmetics started from the Egyptians in 4000BCE; they applied lead ore and copper minerals on the face for definition and color. For eyes, they use kohl, burnt almonds, copper ore, ash, burnt almonds, etc. [4].

In $3000 \mathrm{BCE}$, in nails, Chinese used gum with gelatine, beeswax, and egg as nail paints. In 1500 BCE Japanese used rice powder for face whiting, and henna was used as a coloring agent. From 1200-1300 is called the middle age of cosmetics. At this time, Roman and England used hair colors, e.g., henna [5]. Manufacturing of cosmetics started in 1400-1600 BEC from Europe. European women use various types of products to lighten their skin complexion. AS we know, Queen Elizabeth knows for 'The Mask of Youth' is one well-known use of white lead. For hair paint and lightening from sun exposure of skin, they use a mixture of black sulfur alum and honey [6]. In the 19th \& 20th century, the cosmetic industry developed with lots of new formulations and technology. In this time for face, powder use zinc oxide and replacing the older product with it because in the survey of older one lead and copper apply on the face, 
they create toxicity and health problems including blamed for face tremors, paralysis in muscle even death also $[7,8]$.

\subsection{Definition and use of nanotechnology.}

Nanotechnology is a new type of technology study of forming macromolecules and atoms at the nanoscale. That is, structure, instruments, and systems are designed, manufactured, and characterized at a scale of 1 to $100 \mathrm{~nm}$. A nanometre globule, on the other hand, is 8000 times thinner than the diameter of human hair.

The chemical sciences have also found application in cosmetics, leading to the experimental use of 'nonmaterials' in cosmetic formulation. According to studies, famous companies now use nanosized materials in their different products [9]. Since nanotechnology offers so many possibilities, ''it's a good idea to put it to use. Few cosmetics products are based on the mineral base material, and their action is shown on the base of particle size. As sunscreen products have zinc oxide, and titanium dioxide is used for UV filters. Their particle size range is $20 \mathrm{~nm}$. The influx of applying nanotechnology standards in corrective assembling is extraordinary [10]. Estee Lauder (an enormous restorative maker) supposedly came into the 'nano corrective market' in 2006 with the scope of items including the word" 'Nanoparticles' though L'Oreal is a global cosmetics company. The biggest restorative organization with a base camp in Paris, France, gave nearly 927 million dollars in 2011 to restorative and dermatological research, as well as concocted licenses in a few restorative items having nanomaterial's [11, 12]. A few uses of nanotechnology. But what might start the drive for such consideration and interests in utilizing nano-measured fixings in beautifying agents? Interesting properties and diminished creation cost could be potential reasons [13].

\section{Type of nanotechnology used in cosmetics:}

\subsection{Liposomes.}

Liposomes are bilayered vesicles with concentric layers of fluid; a lipid bilayer is used to encapsulate the volume. Common or manufactured phospholipids, which are for the most part viewed as protected items [14]. Liposomes' lipid bilayer can interact with other bilayers, such as the cell film, to speed up the arrival of their substance, making them useful for corrective conveyance. They are suitable for restorative treatments due to their ease of preparation, improved absorption of active fixings by the skin, and a constant stock of specialists into the cells over a supported timeframe. Vesicles, other than liposomes, are being utilized nowadays that guarantee to additional upgrade the infiltration of substances across the skin, for example, transferases, niosomes, and ethosomes[15, 16]. The negative and positive factors of liposomes are shown in the table.

Table 1. Positive and negative factors of Liposomes.

\begin{tabular}{l|l} 
Positive factor & Negative factor \\
\hline Increased stability & High-cost effective \\
\hline Biodegradable and biocompatible & Low solubility \\
\hline Site avoidance effect & Inadequate stability \\
\hline Increased efficacy & Drug spillage \\
\hline Reduced toxicity & Occasionally, the reactions of oxidation and hydrolysis occur. \\
\hline Easy of penetration in skin layer & Osmotically sensitive
\end{tabular}




\subsection{Nanoemulsions.}

They are nano varying densities beads of one fluid trapped within that. Their systems which are amorphous construction can be modified depending on the technique for readiness. GRAS items are the sections used to evaluate their preparedness, what's more, they are very safe to use. Their more modest corpuscle size gives multistorey security and superior appropriateness they're also used to transport kinematic fixes increment the timeframe of the individual item significant lots [17]. The positive perspectives of nanoemulsions are shown in figure 3 .

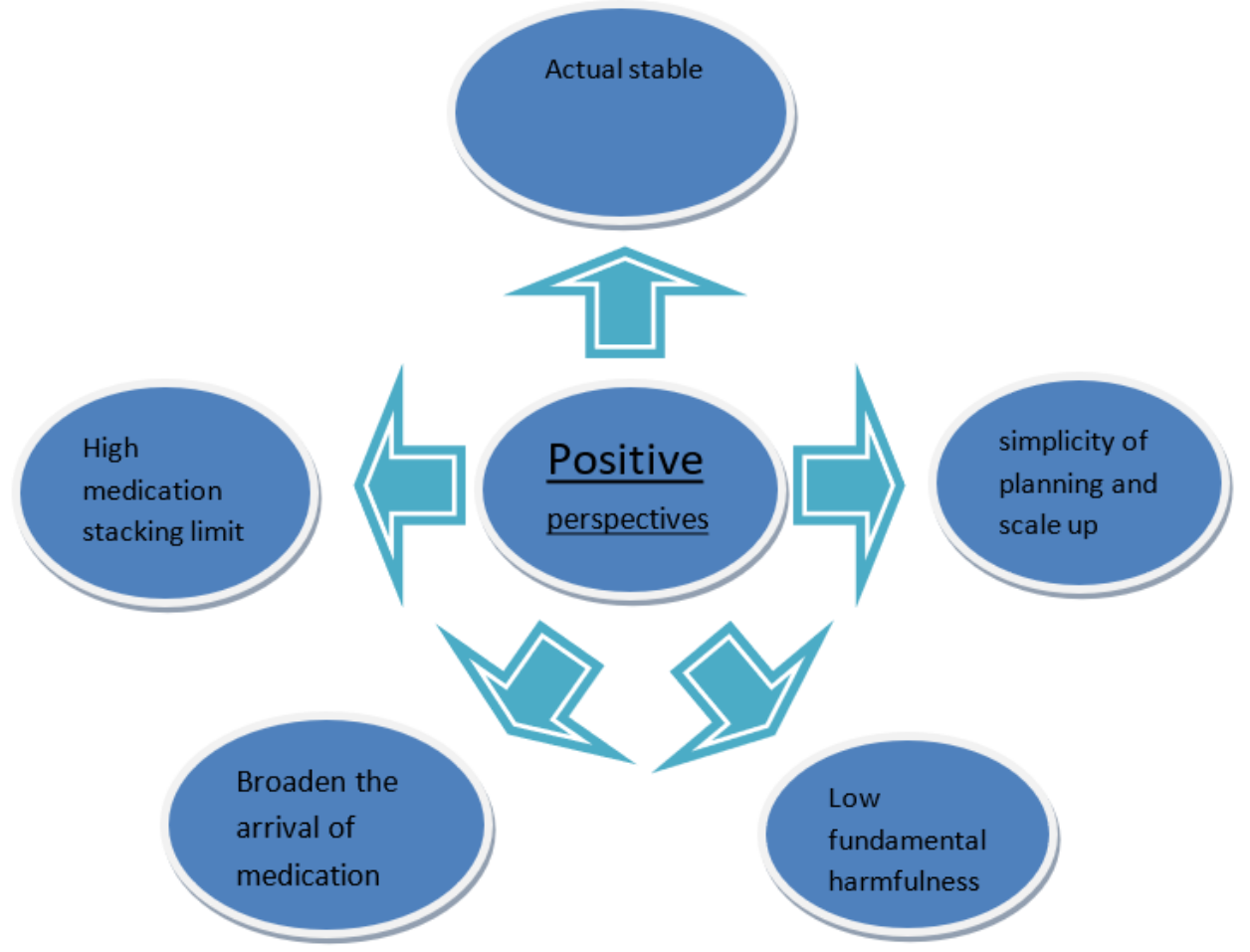

Figure 3. Positive perspectives of nanoemulsion.

\subsection{Nanocapsules.}

Nanocapsules are tiny particles consisting of a polymer materials container encompassing a watery or slick center. It's been a while since tracked down that the utilization of Nanocapsules diminishes the entrance of UV channel octyl methoxycinnamate in pigskin when contrasted and traditional amalgam [18]. Strong they're called lipid nanoparticles sleek beads of sterol that are strong warmth of the human psyche and balanced out by detersive. Polymers can protect the incorporated fixings against decay, utilized for the guarded conveyance of corrective specialists for more than a long period, and it has been discovered that improve the infiltration of zestful compounds through the provides a safety net layer. They've indeed been revealed to have Resin qualities, which were improved until an atomic sunscreen was fused and examined. When 3, 4, 5-trimethoxybenzoylchitin (a good UV barrier) was fused onto SLNs, it improved UV absorbance [18].

\subsection{Nanocrystals.}

They are totals containing a few hundred to several huge numbers of molecules that consolidate into a 'bunch' [19]. Normal sizes of these totals are somewhere in the range of they possess frequencies of 10 and $400 \mathrm{~nm}$. Display corporal and substance movables in the vicinity 
that of the mass firm and atoms. They permit protected and successful entry the skin is undamaged [20].

\subsection{Nanosilver and Nanogold.}

Corrective producers are tackling the upgraded antibacterial properties of nanosilver in the scope of utilizations [21]. Several manufacturers are already offering underarm antiperspirants assert that the silver in the product would provide bactericidal resistance lasting up to 24 hours $[22,23]$. Submicron gold, sometimes termed as nanoparticles, is especially effective in sanitizing oral microbes and has been used in toothpaste [24, 25].

\subsection{Dendrimers.}

Dendrimers are endothermic nanoparticles, micellar nanocrystals with a specified, habitually extended even construction and a high thickness of useful end bunches at their fringes, measuring approximately $20 \mathrm{~nm}$ in size [26, 27]. They contain an enormous number of outer gatherings reasonable for multi-functionalization [28]. The Benefit of Dendrimers is shown in figure 4.

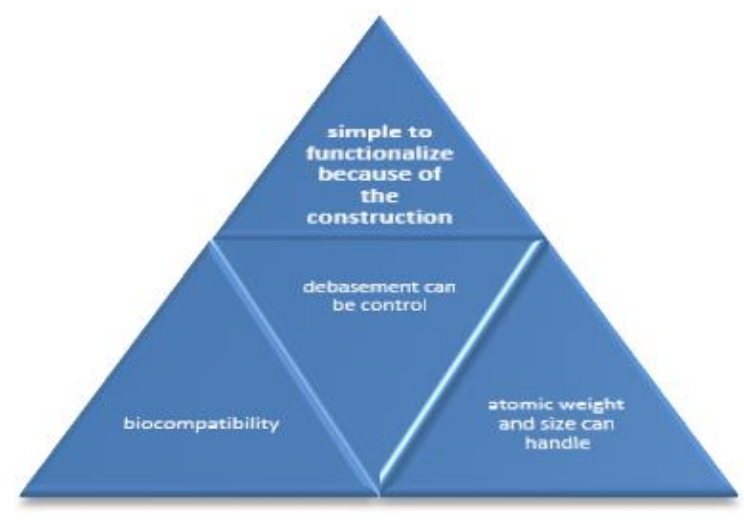

Figure 4. The benefit of dendrimers.

\subsection{Cubosomes.}

Nanotubes are separable, micro, microstructure particles of the trans cubic coolant viscous liquid stage. The individual molds are together of fluid crystalline substance atoms of certain emulsifiers when mixed with liquid and a nanostructure at a fixed space. Nano sponges give a great crystalline structure, typically relate, and can exist at virtually any weaker level. They have excellent giving robustness and are outfitted for imparting amphiphilic atoms [29, 30].

\subsection{Solid lipid nanoparticles.}

A whimsical transporter framework, strong the lipoprotein nanomaterial (Ag - NPS) was created in 1991 as an alternative to the current lipoidal carriers such as emulsifier and transferosomes [31, 32]. 50 to $1000 \mathrm{~nm}$ would be the average diameter of strong microspheres composed of triglycerides [33-36]. These are readied and by complicated glucosides combinations, filtered fatty substances, and waxes; fluid lipid is supplanted by strong lipid or a mix of strong lipid, which is strong done in various physiological and ambient temperatures balanced out by again thermoplastic [37-39]. Lipophilic, hydrophilic, and ineffectively watersolvent dynamic fixings can be joined into SLNs, which comprise lipids that are both 
physiologic and accessible [40, 41]. Biocompatible materials are used mixtures for planning SLN; harmfulness issues are stayed away from. Two guideline techniques for the readiness of SLNs are the towering pressing factor equalization technique and dampness strategy [42-44]. Controlled delivery and supported arrival of the dynamic fixings are conceivable; SLN, which has a drug-enhanced center, prompts a supported delivery Nanocapsules with a drug-advanced shell exhibits a burst discharge [45]. Because they are biodegradable and physiological, SLNs are widely used in organizational and pharmacological applications. Lipids with a low level of eagerness to assist [46-48]. SLNs have occlusive property, which can be utilized to increment the dampness of the skin. Scent definitions also have SLNs as they defer the scent's arrival throughout a longer timeframe and are appropriate for use in creams for the face, too [49]. They have a better strength combination when thought about liposomes since they are strong and portability is diminished of the dynamic particles, so the spillage from the transporter is forestalled [50].

\subsection{Nanostructure lipid carriers (NLC).}

The second age of lipid nanoparticles is defined by nanostructure lipid transporters. [51]. NLC has grown, so the disadvantages related to SLN are a kind of SLN Survived. At body temperature, NLC is formed by mixing strong lipids with spatially contradicting fluid lipids, resulting in shapeless solids in the best proportion of 70: 30 up to 99.9: 0.1. [52]. NLC is predominantly of three sorts on the premise of which the design is created by the plan piece and creation boundaries, in particular, flawed sort, nebulous sort, and numerous sort [53]. The molecule size goes from 10 to $1000 \mathrm{~nm}$ [54]. There is an expanded logical and business consideration due to the decreased risk of basic outcomes, NLC has performed well in recent years. [55]. NLC, when contrasted with SLN shows a higher medication stacking limit with regards to captured bioactive compounds on account of the contorted construction, which helps in making more space [56]. Different impediments of SLN like decreasing molecule focus and ejection of medication during capacity are tackled by the definition of NLC [57]. They are designed using biodegradable and physiological lipids with extremely low toxicity. [58]. NLC features a controlled medication conveyance profile, which is a biphasic drug delivery design in which the medicine is supplied in a burst first, then at a supported rate. [59]. They have various favorable highlights like expanded skin hydration because of their small size. Occlusive characteristics provide intimate contact with the stratum corneum, allowing for greater drug penetration into the skin. [60]. There is steady medication joining during stockpiling and an improved UV insurance framework with decreased results. In October of that year, Nano Repair Q10 cream and Nano Repair Q10 serum, both from Dr. Rimpler GmbH in Germany, were launched to the therapeutic market as the first products containing lipid nanoparticles. There are currently approximately 30 corrective items on the market, which include NLC [61, $62]$.

\section{Application of cosmeceuticals}

\subsection{Uppermost use of nanocosmecuticals.}

Cosmeceuticals are the speediest segment of the confidential healthcare sector. A range of nanocosmecuticals has been used in nail, hair, lip, and pore care, along with skincare. [63]. 


\subsection{Pores and skin wariness.}

Cosmeceuticals for pores and beauty products affect the texture and efficiency of the areas of skin through hyaluronic synthesis is enhanced through opposing the dangerous antioxidants that have an influence [64, 65]. Antioxidants improve the skin condition by retaining the fibroblast arrangement in the proper situation [66].

\subsection{Haircare.}

Skincare products, conditioners, hair growth stimulants, color, and styling products are all examples of hair nano cosmeceutical products. [67]. The accelerated amount of lively ingredient in the hair capillary, shaft, and sebaceous glands are finished through essential residences and precise length of nanotubes [68]. Conditioning nano cosmeceuticals retailers have the purposive characteristic of supplying gentleness, luminosity, musky scent, and luster, and also decorate hair untwisting [69].

\subsection{Lip salve.}

Lip salve merchandise in nano cosmeceuticals incorporates lipstick, lip medicine, lip shine, and lip volumizer. An assortment of nanoparticles can be combined into lip sparkle. Lipstick melts the lips by blocking trans epidermal water misfortune and forestalling the colors from emigrating from the spout and holding color for a long haul. Lip ample liposomes augment lip extent, hydrate and outline the lips, and smooth out wrinkles within the lip contour [70].

\subsection{Nail care.}

Nail care biocosmetics-based nail bother commodity has more supremacy over conventional commodity. The nail enamel primarily based on biocosmetics has deserved, inclusive of progressed sturdiness, rapid dryness, sturdiness, chip intransigence, and ease of utility because of flexibility. A new technique, together with the combo of silver and metal oxide biocosmetics, has antibacterial activity. Homes for the eradication of scabies via lacquer polishes toenails because of fungal infections [71].

\section{Conclusion}

Nanotechnology is viewed as the most encouraging what's more, changing field. Nanotechnology has exploded in popularity during the past decade. In the field of dermatology, it is widely used and beneficial., pharmaceutical applications and beautifiers. Innovations and novel conveyance frameworks have been developed by researchers, which are now being utilized in the production of cosmeceuticals. With such many guaranteed conceivable outcomes of nanoparticles because of their enhanced qualities, the hurry to put them into practice, restorative readiness is on the expansion, and the market is now overwhelmed with so many 'nano-upgraded' skin definitions. Liposomes, noisome, NLC, SLNs, gold nanoparticles, and nanoemulsions are instances of novel nanomedicines that are presently being used. what's more, nanosomes in different cosmeceuticals. Clinical preliminaries are not needed to endorse cosmeceuticals, so the manufacturers appreciate the profit and try not to hold clinical preliminaries and long strategies. Finally, rigid laws ought to be forced on the guideline and security of cosmeceuticals and nanoparticles utilized in them. 


\section{Funding}

This research received no external funding.

\section{Acknowledgments}

\section{The authors are gratefully acknowledged by Pranveer Singh Institute of Technology (PSIT), Kanpur, India, for their assistance with the work.}

\section{Conflicts of Interest}

The authors declare no conflict of interest.

\section{References}

1. Logothetidis, S. Nanostructured materials and their applications. Springer Science \& Business Media, 2012; pp. 1-4, https://doi.org/10.1007/978-3-642-22227-6.

2. Maynard, A.D. A research strategy for addressing risk. Nanotechnology, Woodrow Wilson International Center for Scholars 2006, 444, 267-269.

3. Shah, P.; Gandhi, J.; Kansara, Y.; Barve, K.; Gupta, S. Leveraging Nanotechnology in Cosmeceuticals: Formulation, Characterisation, Regulatory Status and Toxicity. In: Nanocarriers: Drug Delivery System. Springer: 2021; pp. 411-456.

4. Manikanika; Kumar, J.; Jaswal, S. Role of nanotechnology in the world of cosmetology: A review. Materials Today: Proceedings 2021, 45, 3302-3306, https://doi.org/10.1016/j.matpr.2020.12.638.

5. Mittapally, Sirisha, and Amtul Aziz Afnan. "A review on nanotechnology in cosmetics." Pharma Innov J 8 (2019): 668-671.

6. Matike, D.M.E.; Ekosse, G.; Ngole, V.J.I.A.J.o.I.K.S. Indigenous Knowledge Applied to the Use of Clays for Cosmetic Purposes in Africa: An Overview. Indilinga African Journal of Indigenous Knowledge Systems 2010, 9, 138-150.

7. Mpako, M.P.; Matike, E.M.; Ekosse, G.; Ngole, V.E.J.I.A.J.o.I.K.S. Ceremonial Usage of Clays for Body Painting According to Traditional Xhosa Culture. Indilinga African Journal of Indigenous Knowledge Systems 2011, 10, 235-244.

8. Chaudhri, S.K.; Jain, N.K. History of cosmetics. Asian Journal of Pharmaceutics (AJP): Free full text articles from Asian J Pharm 2014, 3.. https://doi.org/10.4103/0973-8398.56292.

9. Lohani, A.; Verma, A.; Joshi, H.; Yadav, N.; Karki, N. Nanotechnology-Based Cosmeceuticals. ISRN Dermatology 2014, 2014, https://doi.org/10.1155/2014/843687.

10. Effiong, D.E.; Uwah, T.O.; Jumbo, E.U.; Akpabio, A.E. Nanotechnology in Cosmetics: Basics, Current Trends and Safety Concerns-A Review. Advances in Nanoparticles 2019, 9, 1-22.

11. Tiwari, Shashank, and Ms Shreya Talreja. "A Concept of Nanotechnology in Cosmetics: A Complete Overview." DOI: 10.37896/aj9.11/003

12. Katz, L.M.; Dewan, K.; Bronaugh, R.L. Nanotechnology in cosmetics. Food and Chemical Toxicology 2015, 85, 127-137, https://doi.org/10.1016/j.fct.2015.06.020.

13. Panariello, L.; Vannozzi, A.; Morganti, P.; Coltelli, M.-B.; Lazzeri, A. Biobased and Eco-Compatible Beauty Films Coated with Chitin Nanofibrils, Nanolignin and Vitamin E. Cosmetics 2021, 8, https://doi.org/10.3390/cosmetics8020027.

14. Gomes, C.S.F.; Santos, D.F.G.; Amaral, M.H.R. Nanominerals and Nanomaterials Utilized in Pharmacy and Therapeutics. In: Minerals latu sensu and Human Health: Benefits, Toxicity and Pathologies. Gomes, C.; Rautureau, M. Eds.; Springer International Publishing: Cham, 2021; pp. 443-475, https://doi.org/10.1007/978-3-030-65706-2_10.

15. Sarma, A.; Bania, R.; Devi, J.R.; Deka, S. Therapeutic nanostructures and nanotoxicity. Journal of Applied Toxicology 2021, https://doi.org/10.1002/jat.4157.

16. Kalepu, S.; Nekkanti, V. Insoluble drug delivery strategies: review of recent advances and business prospects. Acta Pharmaceutica Sinica B 2015, 5, 442-453, https://doi.org/10.1016/j.apsb.2015.07.003.

17. Duarah, S.; Pujari, K.; Durai, R.D.; Narayanan, V.H.B. Nanotechnology-based cosmeceuticals: a review. Int J Appl Pharm 2016, 8, 8-12.

18. Poletto, F.S.; Beck, R.C.R.; Guterres, S.S.; Pohlmann, A.R. Polymeric Nanocapsules: Concepts and Applications. In: Nanocosmetics and Nanomedicines: New Approaches for Skin Care. Beck, R.; Guterres, S.; Pohlmann, A. Eds.; Springer Berlin Heidelberg: Berlin, Heidelberg, 2011; pp. 49-68, https://doi.org/10.1007/978-3-642-19792-5_3.

19. Parmar, P.K.; Wadhawan, J.; Bansal, A.K. Pharmaceutical nanocrystals: A promising approach for improved topical drug delivery. Drug Discovery Today 2021, https://doi.org/10.1016/j.drudis.2021.07.010. 
20. Nath, R.; Chakraborty, R.; Roy, R.; Mukherjee, D.; Nag, S.; Bhattacharya, A. Nanotechnology Based Cosmeceuticals. 2021.

21. Pyo, S.M.; Meinke, M.; Keck, C.M.; Müller, R.H. Rutin-Increased Antioxidant Activity and Skin Penetration by Nanocrystal Technology (smartCrystals). Cosmetics 2016, 3, https://doi.org/10.3390/cosmetics3010009.

22. Merugu, R.; Nayak, B.; Chitturi, K.L.; Kumari Misra, P. Bimetallic silver and copper nanoparticles synthesis, characterization and biological evaluation using aqueous leaf extracts of Majorana hortensis. Materials Today: Proceedings 2021, 44, 2454-2458, https://doi.org/10.1016/j.matpr.2020.12.516.

23. Singh, P.; Nanda, A. Nanotechnology in cosmetics: a boon or bane? Toxicological \& Environmental Chemistry 2012, 94, 1467-1479, https://doi.org/10.1080/02772248.2012.723482.

24. Ali, A.; Sattar, M.; Hussain, F.; Tareen, M.H.; Militky, J.; Noman, M.T. Single-Step Green Synthesis of Highly Concentrated and Stable Colloidal Dispersion of Core-Shell Silver Nanoparticles and Their Antimicrobial and Ultra-High Catalytic Properties. Nanomaterials 2021, 11, https://doi.org/10.3390/nano11041007.

25. Qu, M.; Yao, W.; Cui, X.; Xia, R.; Qin, L.; Liu, X. Biosynthesis of silver nanoparticles (AgNPs) employing Trichoderma strains to control empty-gut disease of oak silkworm (Antheraea pernyi). Materials Today Communications 2021, 28, https://doi.org/10.1016/j.mtcomm.2021.102619.

26. Mukherji, S.; Ruparelia, J.; Agnihotri, S. Antimicrobial Activity of Silver and Copper Nanoparticles: Variation in Sensitivity Across Various Strains of Bacteria and Fungi. In: Nano-Antimicrobials:Progress and Prospects. 2012; pp. 225-251, https://doi.org/10.1007/978-3-642-24428-5_8.

27. Robertson, T.A.; Sanchez, W.Y.; Roberts, M.S. Are Commercially Available Nanoparticles Safe When Applied to the Skin? Journal of Biomedical Nanotechnology 2010, 6, 452-468, https://doi.org/10.1166/jbn.2010.1145.

28. Kumar, I.; Dhiman, S.; Palia, P.; Kumar, P.; Sharma, N. Dendrimers: Potential Drug Carrier For Novel Drug Delivery System. Asian Journal of Pharmaceutical Research and Development 2021, 9, 70-79.

29. Garg, G.; Saraf, S.; Saraf, S. Cubosomes: An Overview. Biological and Pharmaceutical Bulletin 2007, 30, 350-353, https://doi.org/10.1248/bpb.30.350.

30. Aindrilla, S.D.; Harsiddhi, M.C.; Kisan, R.J.; Vilasrao, J.K. Cubosomes: Innovative Nanostructures for Drug Delivery. Current Drug Delivery 2016, 13, 482-493, https://doi.org/10.2174/1567201812666150224114751.

31. Purohit, D.K. Nano-lipid carriers for topical application: Current scenario. Asian Journal of Pharmaceutics (AJP): Free full text articles from Asian J Pharm 2016, 10.

32. Mitkare, S.S.; Gattani, S.G. Recent Nanotechnological Aspects In Cosmetics And Dermatological Preparations. 2012, 4.

33. Kaul, S.; Gulati, N.; Verma, D.; Mukherjee, S.; Nagaich, U. Role of Nanotechnology in Cosmeceuticals: A Review of Recent Advances. Journal of Pharmaceutics 2018, 2018, https://doi.org/10.1155/2018/3420204.

34. Mamulová Kutláková, K.; Tokarský, J.; Kovář, P.; Vojtěšková, S.; Kovářová, A.; Smetana, B.; Kukutschová, J.; Čapková, P.; Matějka, V. Preparation and characterization of photoactive composite kaolinite/TiO2. Journal of Hazardous Materials 2011, 188, 212-220, https://doi.org/10.1016/j.jhazmat.2011.01.106.

35. Abbasi, B.H.; Fazal, H.; Ahmad, N.; Ali, M.; Giglioli-Guivarch, N.; Hano, C. Chapter 5 - Nanomaterials for cosmeceuticals: nanomaterials-induced advancement in cosmetics, challenges, and opportunities. In: Nanocosmetics. Nanda, A.; Nanda, S.; Nguyen, T.A.; Rajendran, S.; Slimani, Y. Eds.; Elsevier: 2020; pp. 79-108, https://doi.org/10.1016/B978-0-12-822286-7.00005-X.

36. Indu, P.K.; Rumjhum, A. Nanotechnology: A New Paradigm in Cosmeceuticals. Recent Patents on Drug Delivery \& Formulation 2007, 1, 171-182, https://doi.org/10.2174/187221107780831888.

37. zur Mühlen, A.; Schwarz, C.; Mehnert, W. Solid lipid nanoparticles (SLN) for controlled drug delivery Drug release and release mechanism. European Journal of Pharmaceutics and Biopharmaceutics 1998, 45, 149-155, https://doi.org/10.1016/S0939-6411(97)00150-1.

38. Pardeike, J.; Hommoss, A.; Müller, R.H. Lipid nanoparticles (SLN, NLC) in cosmetic and pharmaceutical dermal products. International Journal of Pharmaceutics 2009, 366, 170-184, https://doi.org/10.1016/j.ijpharm.2008.10.003.

39. Arora, N.; Agarwal, S.; Murthy, R.S.R. Latest technology advances in cosmaceuticals. International Journal of Pharmaceutical Sciences and Drug Research 2012, 4, 168-182.

40. Patidar, A.; Thakur, D.S.; Kumar, P.; Verma, J. A review on novel lipid based nanocarriers. Int J Pharm Pharm Sci 2010, 2, 30-35.

41. Song, C.; Liu, S. A new healthy sunscreen system for human: Solid lipid nannoparticles as carrier for 3,4,5trimethoxybenzoylchitin and the improvement by adding Vitamin E. International Journal of Biological Macromolecules 2005, 36, 116-119, https://doi.org/10.1016/j.ijbiomac.2005.05.003.

42. Müller, Rainer H., Karsten Mäder, and Sven Gohla. "Solid lipid nanoparticles (SLN) for controlled drug delivery-a review of the state of the art." European journal of pharmaceutics and biopharmaceutics 50, no. 1 (2000): 161-177. https://doi.org/10.1016/S0939-6411(00)00087-4

43. Aboughaly, M.; ElGazayerly, O. Rice bran solid lipid nanoparticles: Preparation and characterization. International Journal of Research in Drug Delivery 2011, 1, 6-9, https://doi.org/10.52403/ijhsr. 
44. Wissing, S.A.; Kayser, O.; Müller, R.H. Solid lipid nanoparticles for parenteral drug delivery. Advanced Drug Delivery Reviews 2004, 56, 1257-1272, https://doi.org/10.1016/j.addr.2003.12.002.

45. Souto, E.B.; Müller, R.H. Cosmetic features and applications of lipid nanoparticles (SLN®, NLC®). International Journal of Cosmetic Science 2008, 30, 157-165, https://doi.org/10.1111/j.14682494.2008.00433.x.

46. Huang, C.-C.; Tang, M.; Tao, W.-H.; Chen, Y.-P. Calculation of the solid solubilities in supercritical carbon dioxide using a modified mixing model. Fluid Phase Equilibria 2001, 179, 67-84, https://doi.org/10.1016/S0378-3812(00)00483-0.

47. Bakthavachalam, A.P.; Remya, N.; Damodharan, N. Review on Solid lipid nanoparticles. Research Journal of Pharmacy and Technology 2020, 13, 4430-4434, http://dx.doi.org/10.5958/0974-360X.2020.00783.0.

48. Umeyor, C.E.; Uronnachi, E.M. Important Pharmaceutical Applications of Man-Made Lipid Nanocarriers for Sustained Drug Delivery and Future Outlook. 2020; pp. 960-967.

49. Chauhan, A.; Chauhan, C. Emerging trends of nanotechnology in beauty solutions: A review. Materials Today: Proceedings 2021, https://doi.org/10.1016/j.matpr.2021.04.378.

50. Waitzberg, D.L.; Torrinhas, R.S. Fish Oil Lipid Emulsions and Immune Response: What Clinicians Need to Know. Nutrition in Clinical Practice 2009, 24, 487-499, https://doi.org/10.1177/0884533609339071.

51. Patel, D.K.; Tripathy, S.; Nair, S.K.; Kesharwani, R. Nanostructured lipid carrier (Nlc) a modern approach for topical delivery: a review. World J. Pharm. Pharm. Sci 2013, 2, 921-938.

52. Campardelli, R.; Cherain, M.; Perfetti, C.; Iorio, C.; Scognamiglio, M.; Reverchon, E.; Della Porta, G. Lipid nanoparticles production by supercritical fluid assisted emulsion-diffusion. The Journal of Supercritical Fluids 2013, 82, 34-40, https://doi.org/10.1016/j.supflu.2013.05.020.

53. Tiwari, A.; Snigdha, B.; Praveen, K.G.; Alok, P.S.; Moumita, B. Potential advancements of nanocarriers in topical drug delivery: a mini review. Letters in Applied NanoBioScience 2020, 9, 968-974, https://doi.org/10.33263/LIANBS92.968974.

54. Purohit, D.K. Nano-lipid carriers for topical application: Current scenario. Asian Journal of Pharmaceutics (AJP): Free full text articles from Asian J Pharm 2016, 10.

55. Youshia, J.; Kamel, A.O.; El Shamy, A.; Mansour, S. Gamma sterilization and in vivo evaluation of cationic nanostructured lipid carriers as potential ocular delivery systems for antiglaucoma drugs. European Journal of Pharmaceutical Sciences 2021, 163, https://doi.org/10.1016/j.ejps.2021.105887.

56. Sun, J.; Liu, J.; Zhang, J.; Xia, H. Meclizine-loaded nanostructured lipid carriers to manage nausea and vomiting: Oral bioavailability improvement. Journal of Drug Delivery Science and Technology 2021, 63, https://doi.org/10.1016/j.jddst.2021.102432.

57. Kumari, S.; Dandamudi, M.; Rani, S.; Behaeghel, E.; Behl, G.; Kent, D.; O’Reilly, N.J.; O’Donovan, O.; McLoughlin, P.; Fitzhenry, L. Dexamethasone-Loaded Nanostructured Lipid Carriers for the Treatment of Dry Eye Disease. Pharmaceutics 2021, 13, https://doi.org/10.3390/pharmaceutics13060905.

58. Azar, Farnaz Ahmadzadeh Nobari, Akram Pezeshki, Babak Ghanbarzadeh, Hamed Hamishehkar, and Maryam Mohammadi. "Nanostructured lipid carriers: Promising delivery systems for encapsulation of food ingredients." Journal of Agriculture and Food Research 2 (2020): 100084. https://doi.org/10.1016/j.jafr.2020.100084

59. Abou Assi, R.; Abdulbaqi, I.M.; Siok Yee, C. The Evaluation of Drug Delivery Nanocarrier Development and Pharmacological Briefing for Metabolic-Associated Fatty Liver Disease (MAFLD): An Update. Pharmaceuticals 2021, 14, https://doi.org/10.3390/ph14030215.

60. Sun, J.; Liu, J.; Zhang, J.; Xia, H. Meclizine-loaded nanostructured lipid carriers to manage nausea and vomiting: Oral bioavailability improvement. Journal of Drug Delivery Science and Technology 2021, 63, https://doi.org/10.1016/j.jddst.2021.102432.

61. Ali, E.S.; Sharker, S.M.; Islam, M.T.; Khan, I.N.; Shaw, S.; Rahman, M.A.; Uddin, S.J.; Shill, M.C.; Rehman, S.; Das, N.; Ahmad, S.; Shilpi, J.A.; Tripathi, S.; Mishra, S.K.; Mubarak, M.S. Targeting cancer cells with nanotherapeutics and nanodiagnostics: Current status and future perspectives. Seminars in Cancer Biology 2021, 69, 52-68, https://doi.org/10.1016/j.semcancer.2020.01.011.

62. Fernandes, F.; Dias-Teixeira, M.; Delerue-Matos, C.; Grosso, C. Critical Review of Lipid-Based Nanoparticles as Carriers of Neuroprotective Drugs and Extracts. Nanomaterials 2021, 11, https://doi.org/10.3390/nano11030563.

63. Bahadur, S.; Pathak, K. Particulate carriers for nose-to-brain delivery. In: Direct Nose-to-Brain Drug Delivery. Elsevier: 2021; pp. 187-207.

64. Roy, D. Aluminum-Doped Nano-Zinc Oxide Can Act as Good Carrier for Biomedicine. In: Advances in Medical Physics and Healthcare Engineering. Springer, Singapore, 2021; pp. 145-152, https://doi.org/10.1007/978-981-33-6915-3_15.

65. Bhattaccharjee, S.; Beck-Broichsitter, M.; Banga, A.K. In Situ Gel Formation in Microporated Skin for Enhanced Topical Delivery of Niacinamide. Pharmaceutics 2020, 12, https://doi.org/10.3390/pharmaceutics12050472.

66. Kim, Y.; Bhattaccharjee, S.A.; Beck-Broichsitter, M.; Banga, A.K. Fabrication and characterization of hyaluronic acid microneedlesto enhance delivery of magnesium ascorbyl phosphate into skin. Biomedical Microdevices 2019, 21, 1-9, https://doi.org/10.1007/s10544-019-0455-0. 
67. Costa, C.; Fernandes, B.; Guimarães, D.; Nogueira, E.; Martins, M.; Matamá, T.; Cavaco-Paulo, A. Comparing the delivery to the hair bulb of two fluorescent molecules of distinct hydrophilicities by different nanoparticles and a serum formulation. International Journal of Pharmaceutics 2021, 602, https://doi.org/10.1016/j.ijpharm.2021.120653.

68. Chavan, R.R.; Bhinge, S.D.; Bhutkar, M.A.; Randive, D.S.; Wadkar, G.H.; Todkar, S.S. In vivo and in vitro hair growth-promoting effect of silver and iron nanoparticles synthesized via Blumea eriantha DC plant extract. Journal of Cosmetic Dermatology 2021, 20, 1283-1297, https://doi.org/10.1111/jocd.13713.

69. Kushwaha, N.; Minocha, N.; Kumar, N. Use of nanotechnology in cosmeceuticals: a review. Int J Pharm Sci Invent 2020, 9, 43-51.

70. Abbasi, B.H.; Fazal, H.; Ahmad, N.; Ali, M.; Giglioli-Guivarch, N.; Hano, C. Chapter 5 - Nanomaterials for cosmeceuticals: nanomaterials-induced advancement in cosmetics, challenges, and opportunities. In: Nanocosmetics. Nanda, A.; Nanda, S.; Nguyen, T.A.; Rajendran, S.; Slimani, Y. Eds.; Elsevier: 2020; pp. 79108, https://doi.org/10.1016/B978-0-12-822286-7.00005-X.

71. El-Gendy, N.S.; Omran, B.A. 21 - Sustainable green synthesized nanoparticles: bioapplications and biosafety. In: Removal of Toxic Pollutants Through Microbiological and Tertiary Treatment. Shah, M.P. Ed.; Elsevier: 2020; pp. 549-586, https://doi.org/10.1016/B978-0-12-821014-7.00021-6. 